\title{
Influence of Overaging on the Superplastic Behavior of an Al-Zn-Mg-Cu-Zr-Sc Alloy
}

\author{
Yi-Yun $\mathrm{Li}^{1}$, Wen-Hsiung Wang ${ }^{1, *}$, Yung-Fu Hsu ${ }^{2}$, You-Luen Chang ${ }^{1}$ and Shan Trong ${ }^{3}$ \\ ${ }^{1}$ Department of Materials Science and Engineering, National Taiwan University, Taipei, Taiwan 106, R. O. China \\ ${ }^{2}$ Department of Materials and Mineral Resources Engineering, National Taipei University of Technology, \\ Taipei, Taiwan 106, R. O. China \\ ${ }^{3}$ Materials and Electro-Optics Research Division, Chung-Shan Institute of Science and Technology, \\ Lung-Tan, Taiwan 325, R. O. China
}

This study examines the influence of overaging on the superplastic behavior of an Al-8.55Zn-2.65Mg-2.48Cu-0.1Zr-0.06Sc alloy (in mass\%). Results show that the M-phase particles formed during overaging play the most crucial role during the high-temperature tensile deformation of the $\mathrm{Al}-\mathrm{Zn}-\mathrm{Mg}-\mathrm{Cu}-\mathrm{Zr}-\mathrm{Sc}$ alloy. Even though specimens without overaging maintain their small grain structure due to the existence of fine coherent $\mathrm{Al}_{3}\left(\mathrm{Sc}_{x} \mathrm{Zr}_{1-x}\right)$ particles, overaged specimens exhibit better superplasticity. The presence of liquid-like viscous flow may be the main factor contributing to the superior superplasticity of overaged specimens. [doi:10.2320/matertrans.MRA2008197]

(Received June 23, 2008; Accepted January 6, 2009; Published February 25, 2009)

Keywords: high-strength aluminum alloy, overaging, superplastic, $A l_{3}\left(S c_{x} Z r_{1-x}\right)$

\section{Introduction}

Superplastic forming is an attractive manufacturing process, and is widely used in numerous alloy systems. Superplastic forming of aluminum alloys allows the fabrication of complex sheet-metal components for automobile and aerospace applications. Superplastic forming requires small and stable grains which are usually less than $10 \mu \mathrm{m}$ in diameter. ${ }^{1)}$ In high-strength 7XXX Al alloys, various thermomechanical processes (TMP) have been developed to produce a fine grain structure. The TMP first proposed by Wert et al. for 7475 and 7075 alloys is the most famous of these processes, and is considered to be an effective grain refinement method for $\mathrm{Al}-\mathrm{Zn}-\mathrm{Mg}(-\mathrm{Cu})$ alloys. $^{2)}$ A typical TMP involves solution treatment, overaging at $400^{\circ} \mathrm{C}$, warm rolling, and annealing. During the overaging stage, coarse secondary particles, which are a type of $\mathrm{Al}-\mathrm{Zn}-\mathrm{Mg}(-\mathrm{Cu})$ compound known as $\mathrm{M}-$ phase, can form in the $\mathrm{Al}-\mathrm{Zn}-\mathrm{Mg}(-\mathrm{Cu})$ alloys. These particles act as nucleation sites for recrystallization, thereby refining the grain structure and enhancing the superplasticity of the $\mathrm{Al}-\mathrm{Zn}-\mathrm{Mg}(-\mathrm{Cu})$ alloys.

In traditional fine-grained $\mathrm{Al}-\mathrm{Mg}$ alloys, superplasticity is limited due to significant grain growth during superplastic deformation. ${ }^{3,4)}$ Thus, it is important to find an effective grain stabilizing agent for superplastic Al-Mg alloys. Adding Sc as an alloying element is considered to be the most effective way to improve the properties of Al-Mg alloys. Further, the effects of Sc can be greatly amplified by Zr. Therefore, the high-temperature tensile behavior of Al-Mg alloys can be enhanced by adding Sc and $\mathrm{Zr}^{5}{ }^{5}$ ) The extremely fine and coherent $\mathrm{Al}_{3}\left(\mathrm{Sc}_{x} \mathrm{Zr}_{1-x}\right)$ particles are more thermally stable than $\mathrm{Al}_{3} \mathrm{Sc}$ or $\mathrm{Al}_{3} \mathrm{Zr}$ particles at elevated temperatures,, 57$)$ which provides greater inhibition of grain growth at high temperatures. ${ }^{8)}$

Although many studies have examined superplastic Al$\mathrm{Zn}-\mathrm{Mg}(-\mathrm{Cu})$ alloys $^{9-12)}$ and the effects of $\mathrm{Sc}$ and $\mathrm{Zr}$ on the high-temperature tensile behavior of $\mathrm{Al}-\mathrm{Mg}$ alloys, ${ }^{5-8,13}$ )

*Corresponding author, E-mail: whwang@ntu.edu.tw few studies discuss the superplastic behavior of highstrength $\mathrm{Al}-\mathrm{Zn}-\mathrm{Mg}-\mathrm{Cu}-\mathrm{Zr}-\mathrm{Sc}$ alloys. To address this gap, the current study examines the influences of overaging and $\mathrm{Al}_{3}\left(\mathrm{Sc}_{x} \mathrm{Zr}_{1-x}\right)$ particles on the high-temperature deformation behavior of Al-Zn-Mg-Cu-Zr-Sc alloys.

\section{Experimental Procedures}

Chung-Shan Institute of Science and Technology (Taiwan) supplied the material used in this study. This sample material had a chemical composition of $8.55 \mathrm{Zn}$, $2.65 \mathrm{Mg}, 2.48 \mathrm{Cu}, 0.1 \mathrm{Zr}, 0.06 \mathrm{Sc}, 0.04 \mathrm{Fe}, 0.03 \mathrm{Mn}, 0.02 \mathrm{Ti}$, $0.04 \mathrm{Si},<0.01 \mathrm{Cr}$ (mass\%), with Al filling the balance. The alloy was received in an extruded form with a thickness of $12 \mathrm{~mm}$. The TMP concept proposed by Wert et al. ${ }^{2)}$ was applied to this alloy. The alloy was first hot-rolled at $450^{\circ} \mathrm{C}$ to a thickness of $9 \mathrm{~mm}$. Solution treatment was conducted in an air furnace at $470^{\circ} \mathrm{C}$ for $4 \mathrm{~h}$ followed by water quenching. Some specimens of the material were then overaged at $400^{\circ} \mathrm{C}$ for $8 \mathrm{~h}$. Both types of specimens, with and without overaging, were finally warm-rolled at $200^{\circ} \mathrm{C}$ to a final thickness of $2 \mathrm{~mm}$, representing a reduction of $77 \%$. In this study, specimens with overaging are called TMP-A and specimens without overaging are called TMP-B. To more clearly and easily investigate the performance of $\mathrm{Al}_{3}\left(\mathrm{Sc}_{x} \mathrm{Zr}_{1-x}\right)$ and coarse secondary particles during the high-temperature tensile deformation of the $\mathrm{Al}-\mathrm{Zn}-\mathrm{Mg}-\mathrm{Cu}-$ $\mathrm{Zr}-\mathrm{Sc}$ alloy, this study omits the final high-temperature annealing in Wert et al.'s research. ${ }^{2)}$ This is because final high-temperature annealing would dissolve most of the coarse secondary particles in TMP-A in matrix.

Tensile specimens with a gauge length of $10 \mathrm{~mm}$ and cross section of $6 \times 2 \mathrm{~mm}^{2}$ were machined from TMP-A and TMP-B sheets, with the loading axis parallel to the rolling direction. Tensile tests were conducted at temperatures between $300^{\circ} \mathrm{C}$ and $450^{\circ} \mathrm{C}$ at a strain rate range of $1 \times 10^{-2}$ $2 \times 10^{-4} \mathrm{~s}^{-1}$. The highest working temperature $450^{\circ} \mathrm{C}$ was selected based on the DSC experiment that eutectic melting occurred above $485^{\circ} \mathrm{C}$ to avoid liquid formation. All high- 


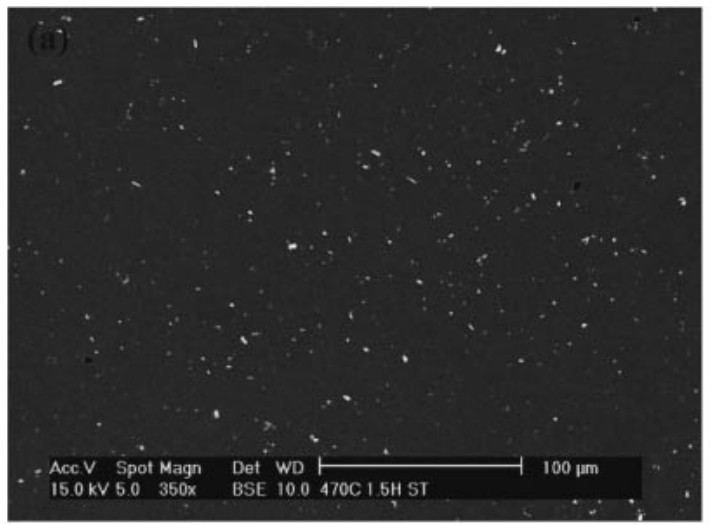

(c)
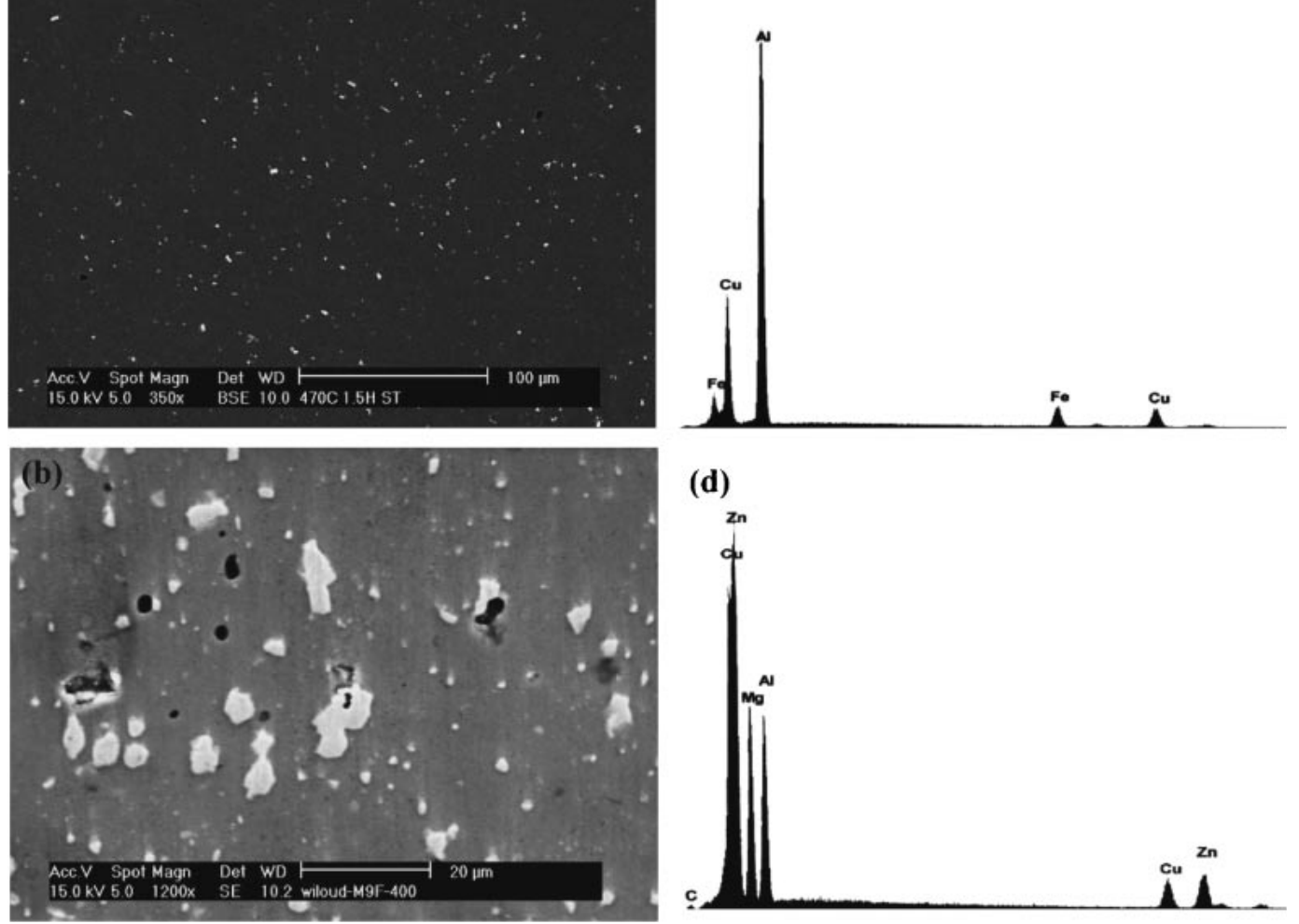

(d)

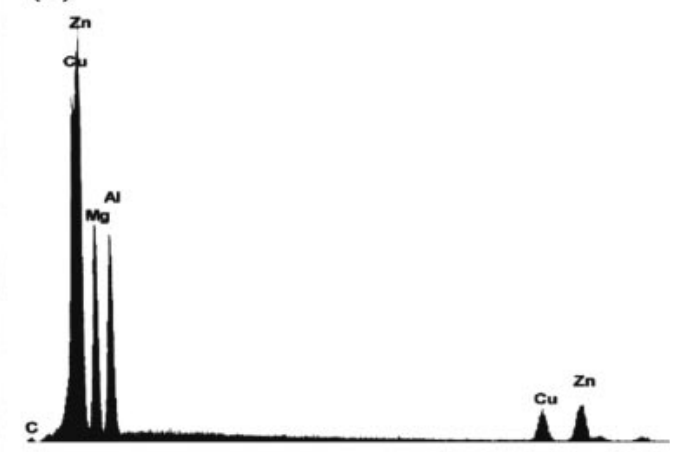

Fig. 1 SEM microstructure of the Al-Zn-Mg-Cu-Zr-Sc alloy after: (a) solution treatment and (b) overaging; (c) and (d) shows EDS analysis result of the white particles in (a) and (b), respectively.

temperature tensile tests were conducted on a Hung-Ta HT8150 materials test system with a five-zone furnace operating at a constant crosshead displacement rate. The value of the strain rate sensitivity, $m$, was determined according to the following equation:

$$
m=\frac{\partial \log \sigma}{\partial \log \dot{\varepsilon}}
$$

This study used optical microscopy (OM), scanning electron microscopy (SEM) and transmission electron microscopy (TEM) to examine the microstructure of the Al-Zn$\mathrm{Mg}-\mathrm{Cu}-\mathrm{Zr}-\mathrm{Sc}$ alloy after high-temperature tensile tests. The samples chosen for TEM observations were prepared by mechanical grinding to a thickness of about $10 \mu \mathrm{m}$, and further thinned to a thickness of electron transparency using double-jet electro-polishing in a $25 \%$ nitric acid and $75 \%$ methanol solution operated at around $-30^{\circ} \mathrm{C}$ and $30 \mathrm{~V}$. Samples were examined on a JOEL-100CXII microscope operating at $100 \mathrm{kV}$.

\section{Results}

\subsection{Microstructure of thermomechanically processed specimens}

Figures 1(a) and (b) show the influence of overaging on the microstructure of the Al-Zn-Mg-Cu-Zr-Sc alloy. Figure 1(a) is the BSE image of the Al-Zn-Mg-Cu-Zr-Sc alloy after solution heat treatment. Some small white inclusions appear in the matrix, and most of them are $\mathrm{Al}_{7} \mathrm{Cu}_{2} \mathrm{Fe}$ compounds (Fig. 1(c)). These $\mathrm{Al}_{7} \mathrm{Cu}_{2} \mathrm{Fe}$ compounds are insoluble by solution treatment, and usually appear in highstrength Al-Zn-Mg-Cu-Zr-Sc alloys. ${ }^{8)}$ Figure 1(b) is the BSE image of TMP-A after overaging treatment at $400^{\circ} \mathrm{C}$ for $8 \mathrm{~h}$. Coarse secondary particles formed during overaging are present in the alloy, and can be identified as $\mathrm{Al}-\mathrm{Zn}-\mathrm{Mg}-\mathrm{Cu}$ compounds (Fig. 1(d)). These coarse Al-Zn-Mg-Cu compounds, also known as M-phase, can introduce higher strain energy during warm-rolling and act as nucleation sites to refine grain structure during recrystallization. ${ }^{2)}$

Figures 2(a)-(d) show the TEM images of TMP-A and TMP-B in the as-rolled state. Both Fig. 2(a) and (b) show the typical highly deformed microstructure of Al alloys. Several coarse and small hollows appear in TMP-A (Fig. 2(a)). The interfaces between the M-phase particles and the matrix introduce a chemical potential difference that accelerate the dissolution of the interfaces. Therefore, the coarse hollows in TMP-A can be regarded as the original sites of coarse M-phase particles, and small hollows are the sites of smaller M-phase particles or $\mathrm{Al}_{7} \mathrm{Cu}_{2} \mathrm{Fe}$ particles. Figure 2(b) shows that few hollows appear in TMP-B. Figures 2(c) and (d) are the corresponding TEM images of Figs. 2(a) and (b), respectively, at a higher magnification. Both small round $\mathrm{M}$-phase particles and fine spherical $\mathrm{Al}_{3}\left(\mathrm{Sc}_{x} \mathrm{Zr}_{1-x}\right)$ particles appear in TMP-A and TMP-B in the as-rolled state. These small round M-phase particles mostly form during warm-rolling at $200^{\circ} \mathrm{C}$, while the fine spherical $\mathrm{Al}_{3}\left(\mathrm{Sc}_{x} \mathrm{Zr}_{1-x}\right)$ particles mostly form during material making processes such as casting, homogenization, and extrusion. Both of these particles interact with dislocations during warm-rolling. 

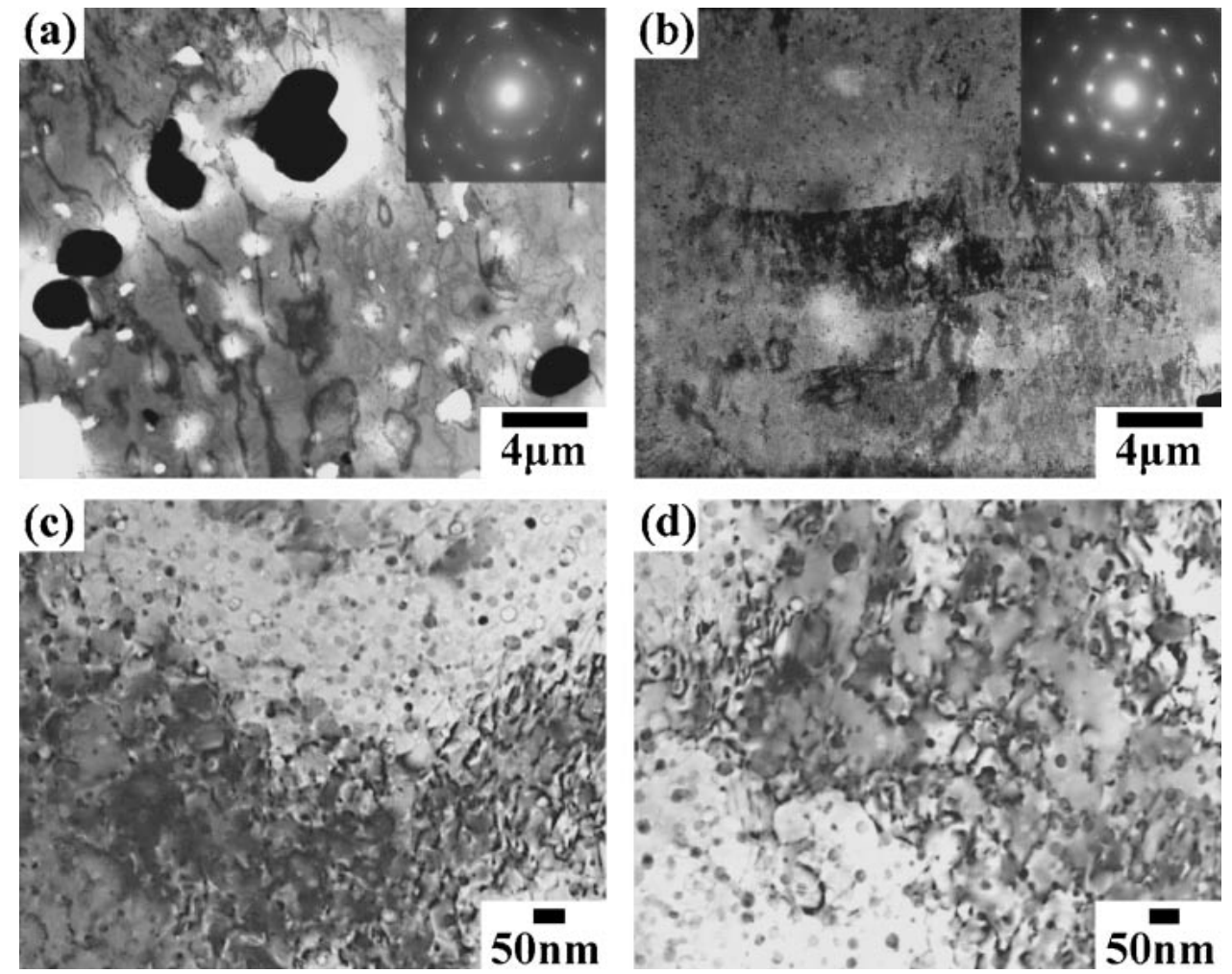

Fig. 2 TEM micrographs of (a) TMP-A and (b) TMP-B; (c) and (d) are the higher magnification of (a) and (b), respectively.
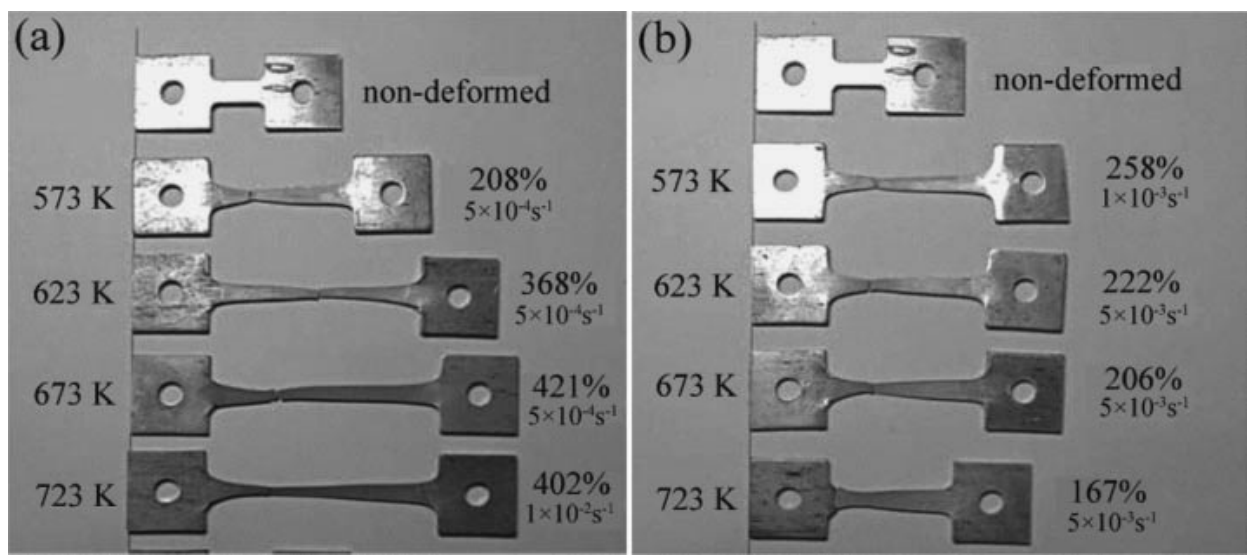

Fig. 3 Appearances of the optimal elongation at various temperatures of (a) TMP-A and (b) TMP-B.

\subsection{High-temperature tensile behavior}

Figures 3(a) and (b) show the optimal elongation at various temperatures for TMP-A and TMP-B, respectively. These figures show that TMP-A exhibits better ductility than TMP-B at temperatures ranging from $350-450^{\circ} \mathrm{C}$. The hightemperature tensile behaviors of both TMP-A and TMP-B are not very outstanding. The maximum elongation in TMP-A was just $421 \%$ at $400^{\circ} \mathrm{C}$ and $5 \times 10^{-4} \mathrm{~s}^{-1}$. However, TMP-A achieved an acceptable elongation of $402 \%$ when deformed at $450^{\circ} \mathrm{C}$ and $1 \times 10^{-2} \mathrm{~s}^{-1}$. The strain rate $1 \times 10^{-2} \mathrm{~s}^{-1}$ is high, and an elongation of $402 \%$ is acceptable in common superplastic applications. ${ }^{14)}$ The barely acceptable ductility performance of TMP-A may be due to the elimination of the final recrystallization step used in Wert et al.'s study. ${ }^{2)}$ The alloy could not achieve the equiaxed grain structure essential to the sliding of the grain boundary. Figures 4(a)- (d) show the true stress-strain curves of TMP-A and TMP-B specimens deformed at strain rates of $1 \times 10^{-2} \mathrm{~s}^{-1}$ and $5 \times 10^{-4} \mathrm{~s}^{-1}$ at various temperatures. At a higher strain rate of $1 \times 10^{-2} \mathrm{~s}^{-1}$ (Fig. 4(a) and (b)), TMP-A has a higher flow stress than TMP-B a temperatures ranging from $300-400^{\circ} \mathrm{C}$, while at $450^{\circ} \mathrm{C}$, TMP-A had a lower flow stress than TMP-B. In addition, at a lower strain rate of $5 \times 10^{-4} \mathrm{~s}^{-1}$ (Fig. 4(c) and (d)), the flow stress of TMP-A remained higher than TMP-B at $300^{\circ} \mathrm{C}$, while the flow stress of TMP-A was lower than TMP-B above $350^{\circ} \mathrm{C}$.

Figures 5(a) and (b) show the TEM images of the grain structures of TMP-A and TMP-B after high-temperature deformation at $450^{\circ} \mathrm{C}$ and $1 \times 10^{-2} \mathrm{~s}^{-1}$, and $400^{\circ} \mathrm{C}$ and $5 \times 10^{-3} \mathrm{~s}^{-1}$, respectively. Both specimens experienced approximately the same testing period, including $15 \mathrm{mins}$ isothermal holding and nearly 7 mins deformation time, and 

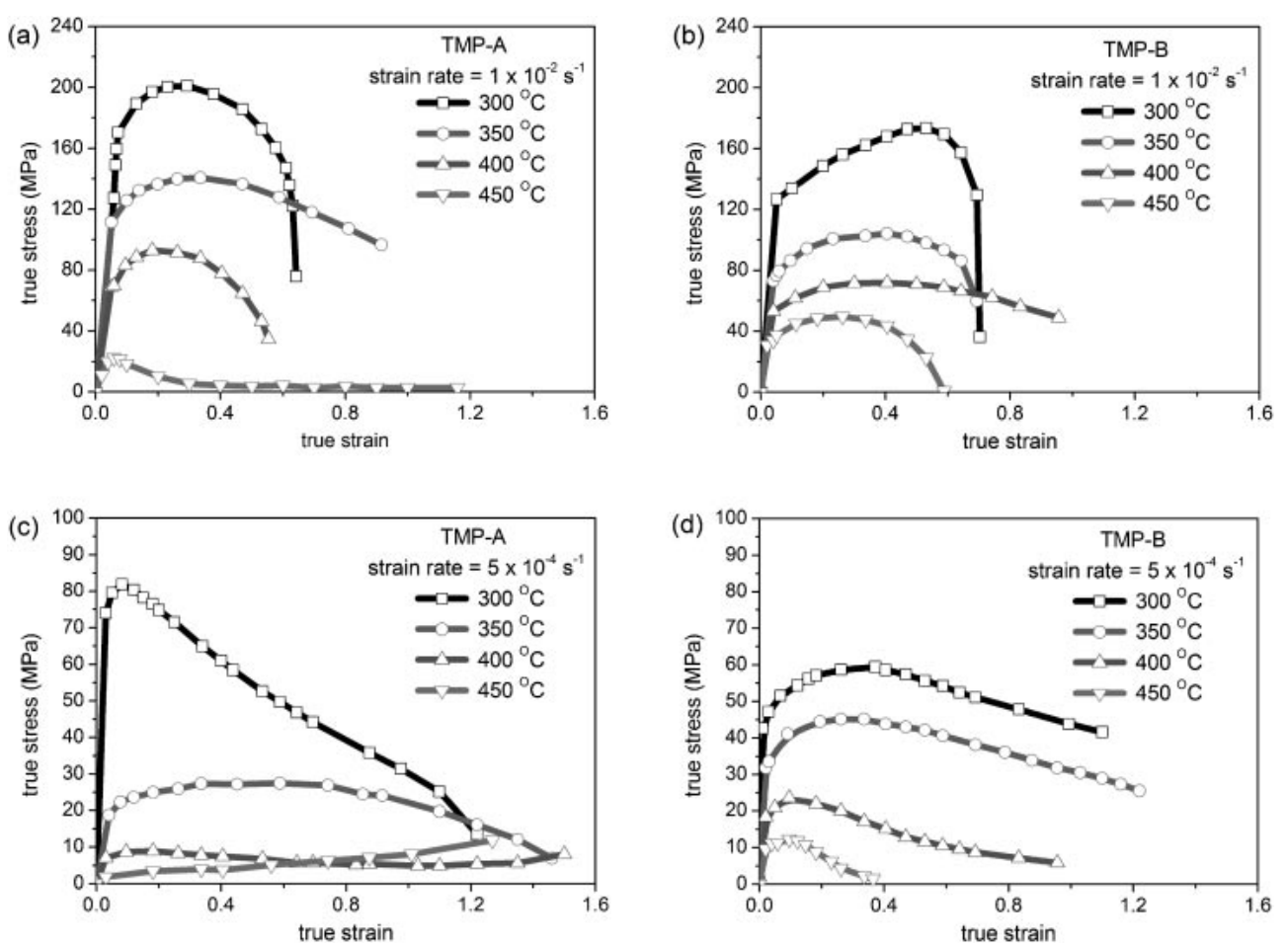

Fig. 4 True stress-strain curves of TMP-A and TMP-B tested at strain rates of $1 \times 10^{-2} \mathrm{~s}^{-1}$ and $5 \times 10^{-4} \mathrm{~s}^{-1}$ at various temperatures.
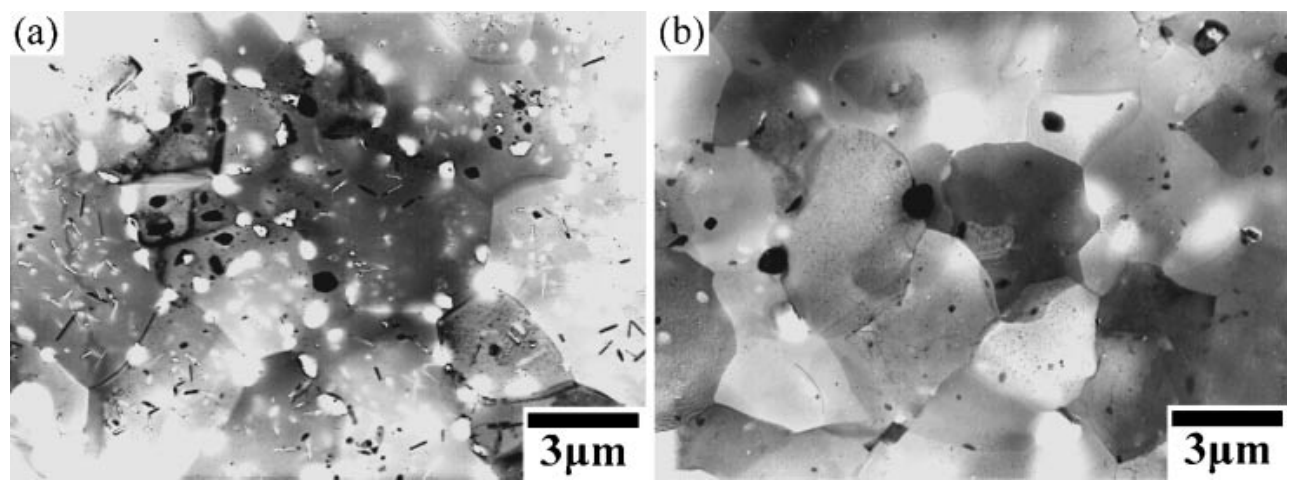

Fig. 5 TEM microstructure of (a) TMP-A after deformation at $450^{\circ} \mathrm{C}$ and $1 \times 10^{-2} \mathrm{~s}^{-1}$ and (b) TMP-B after deformation at $400^{\circ} \mathrm{C}$ and $5 \times 10^{-3} \mathrm{~s}^{-1}$.

showed a very small grain size of $3 \mu \mathrm{m}$. Many small hollows appear in the grain boundaries in the TMP-A sample, while only few hollows appear in the TMP-B grain boundaries. The incompletely dissolved coarse $\mathrm{M}$-phase particles remaining after high-temperature deformation generated these small hollows.

Fine and coherent spherical $\mathrm{Al}_{3}\left(\mathrm{Sc}_{x} \mathrm{Zr}_{1-x}\right)$ particles also appear in both TMP-A and TMP-B specimens after hightemperature deformation (Fig. 6). These particles are extremely small: $23 \mathrm{~nm}$ in TMP-A after deformation at $450^{\circ} \mathrm{C}$ and $1 \times 10^{-2} \mathrm{~s}^{-1} ; 18 \mathrm{~nm}$ in TMP-B after deformation at $400^{\circ} \mathrm{C}$ and $5 \times 10^{-3} \mathrm{~s}^{-1}$. The TMP-A and TMP-B specimens exhibit no great differences in the size and the density of $\mathrm{Al}_{3}\left(\mathrm{Sc}_{x} \mathrm{Zr}_{1-x}\right)$ particles. These particles had strong interaction with the dislocations (Fig. 6(b)) and the grain boundaries during deformation. ${ }^{13)}$ In TMP-A (Fig. 6(c)), both the coarse M-phase particles and the $\mathrm{Al}_{3}\left(\mathrm{Sc}_{x} \mathrm{Zr}_{1-x}\right)$ particles strongly interacted with the grain boundaries. On the other hand, the coarse secondary particles were absent from the grain boundary interaction in TMP-B (Fig. 6(d)). The $\mathrm{Al}_{3}\left(\mathrm{Sc}_{x} \mathrm{Zr}_{1-x}\right)$ particles effectively maintained the fine grain structure in TMP-B (Fig. 5(b)).

\subsection{Fracture behavior}

Figures 7(a) and (b) show the SEM fractographs of TMP$\mathrm{A}$ and TMP-B specimens after high-temperature tensile deformation at $400^{\circ} \mathrm{C}$ and $5 \times 10^{-4} \mathrm{~s}^{-1}$. Both the TMP-A and TMP-B fracture modes were intergranular that the topography of the grains was clearly seen. Whiskers on the TMP-A fracture surface were also observed (Fig. 7(a)), whereas no whiskers were found in TMP-B (Fig. 7(b)). The TMP-A whisker formation at a strain rate of $5 \times 10^{-4} \mathrm{~s}^{-1}$ occurred in a temperature range of $350-450^{\circ} \mathrm{C}$, which is close to the overaging temperature of $400^{\circ} \mathrm{C}$. Notice that TMP-A exhibits lower flow stress than TMP-B at a strain rate of $5 \times 10^{-4} \mathrm{~s}^{-1}$ (Figs. 4(a) and (b)) at temperatures ranging from $350-450^{\circ} \mathrm{C}$. These whiskers frequently appear in high-strength 7XXX aluminum alloys after high-temper- 

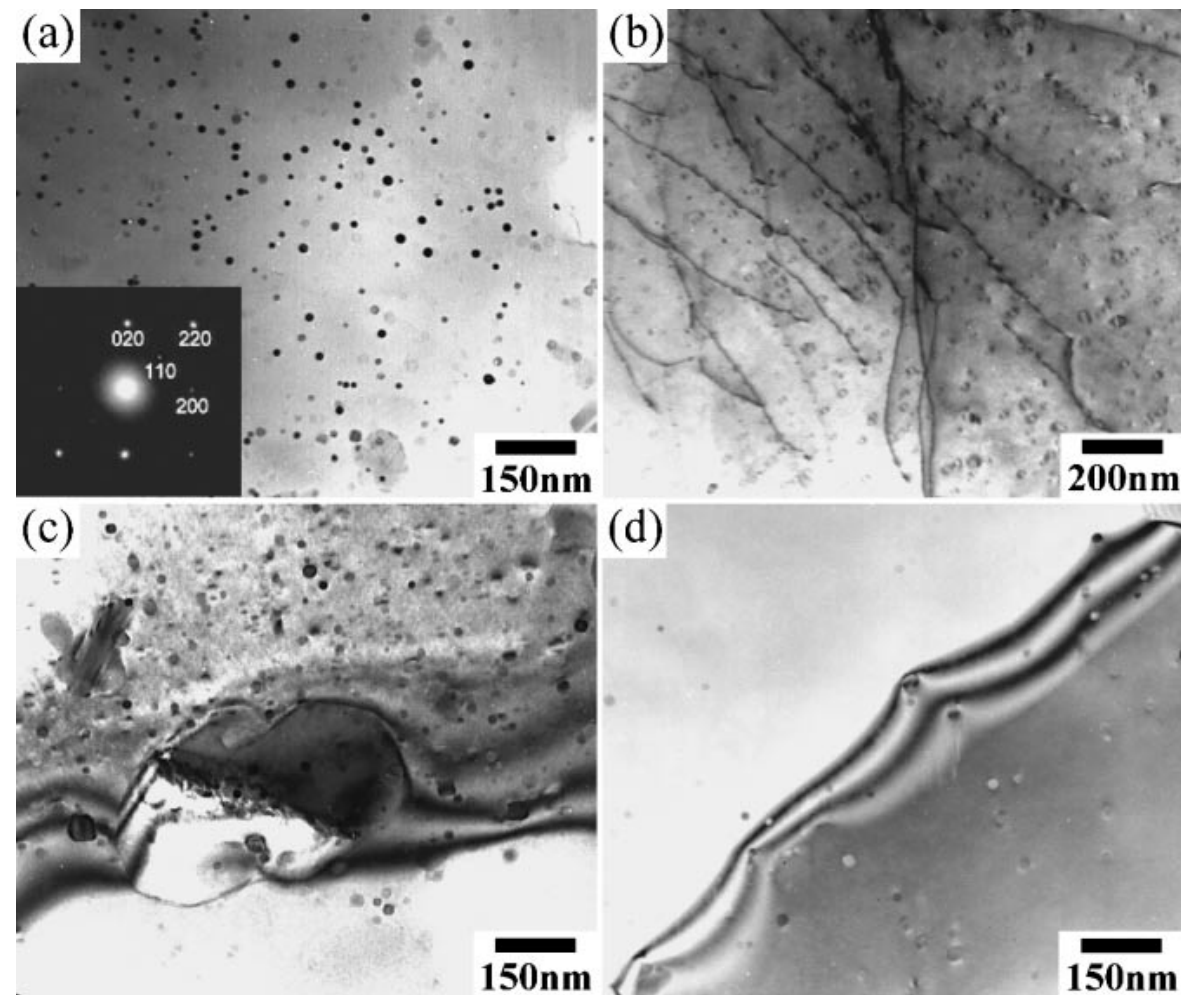

Fig. 6 TEM micrographs of: (a) the $\mathrm{Al}_{3}\left(\mathrm{Sc}_{x} \mathrm{Zr}_{1-x}\right)$ particles and (b) the interaction between the $\mathrm{Al}_{3}\left(\mathrm{Sc}_{x} \mathrm{Zr}_{1-x}\right)$ particles and dislocations in TMP-B after deformation at $400^{\circ} \mathrm{C}$ and $5 \times 10^{-3} \mathrm{~s}^{-1}$; the grain boundaries of (c) TMP-A after pulling to failure at $450^{\circ} \mathrm{C}$ and $1 \times 10^{-2} \mathrm{~s}^{-1}$ and (d) TMP-B after deformation at $400^{\circ} \mathrm{C}$ and $5 \times 10^{-3} \mathrm{~s}^{-1}$.

ature tensile deformation, and are thought to be evidence for a liquid-like viscous flow originating at the grain boundaries. ${ }^{12)}$ In addition, the grain size of TMP-B $(\sim 6 \mu \mathrm{m})$ remained quite small after deformation, which is even smaller than TMP-A $(\sim 9 \mu \mathrm{m})$. Though superplastic is feasible in small grains, typically less than $10 \mu \mathrm{m}$, the high-temperature tensile behavior of TMP-B was quite poor. Figures 7(c) and (d) show the fractographs of TMP-A and TMP-B after deformation at $450^{\circ} \mathrm{C}$ and $1 \times 10^{-2} \mathrm{~s}^{-1}$. In this case, TMP-A specimens had a flow stress lower than TMP-B. The topography of TMP-A grains was "wet", which is also an evidence of the partial melting of Mphase particles. On the other hand, the topography of TMP-B was "dry", which indicates typical ductile fracture characteristics.

Figures 8(a) and (b) show the OM images of the gauge sections near the fracture tip of TMP-A and TMP-B after deformation at $400^{\circ} \mathrm{C}$ and $5 \times 10^{-4} \mathrm{~s}^{-1}$. These figures show that TMP-A endured more cavitations than TMP-B. Comparing to Fig. 7(a) and (b), even with the absence of coarse M-phase particles, the grains in TMP-B remain small, and even smaller than grains in TMP-A after deformation.

\section{Discussion}

\subsection{High-temperature tensile behavior of overaged specimens}

Coarse M-phase particles forming during the overaging process can serve as recrystallization nucleation sites, thereby refining the grain structure of $\mathrm{Al}-\mathrm{Zn}-\mathrm{Mg}(-\mathrm{Cu})$ alloys. ${ }^{6)} \mathrm{In}$ addition, these particles appear to inhibit grain growth and maintain a fine grain structure during high-temperature tensile deformation (Figs. 5(a) and 6(c)). Moreover, Fig. 7(a) and (c) show that adequate partial melting of the coarse Mphase particles can enhance solvent diffusivity and form a liquid-like diffusion flow. ${ }^{12}$ This liquid-like diffusion flow lubricates the grain boundary during high-temperature deformation, and in turn, relaxes the stress concentration at the junction of the grain boundaries. Therefore, when tested at a lower strain rate of $5 \times 10^{-4} \mathrm{~s}^{-1}$ (Fig. 4(c) and (d)), partial melting of the M-phases particles at $350-450^{\circ} \mathrm{C}$ had sufficient time to let the solvent atoms diffuse. This in turn releases the stress concentration at the grain boundaries, and reduces the flow stress in TMP-A to be even lower than TMPB. At a higher strain rate of $1 \times 10^{-2} \mathrm{~s}^{-1}$, the liquid-like diffusion flow can only effectively offset the stress accumulation at grain boundaries when deformed at a high temperature of $450^{\circ} \mathrm{C}$ where diffusion is very fast, as a result, the flow stress of TMP-A was lower than TMP-B at temperature of $450^{\circ} \mathrm{C}$ (Figs. 4(a) and (b)). The reduction of flow stress in Fig. 4 may be evidence for strain energy releasing caused by the partial melting of coarse M-phase particles. Jiang et al. produced similar results, in that the strain hardening of overaged specimens was lower than that of non-overaged specimens. ${ }^{15)}$

Figures 8(a) and (b) show that the liquid-like diffusion flow may help withstand higher void coalescences during high-temperature tensile deformation. ${ }^{12}$ )

\subsection{High-temperature tensile behavior of non-overaged specimens}

The combination of $\mathrm{Sc}$ and $\mathrm{Zr}$ additives causes the 

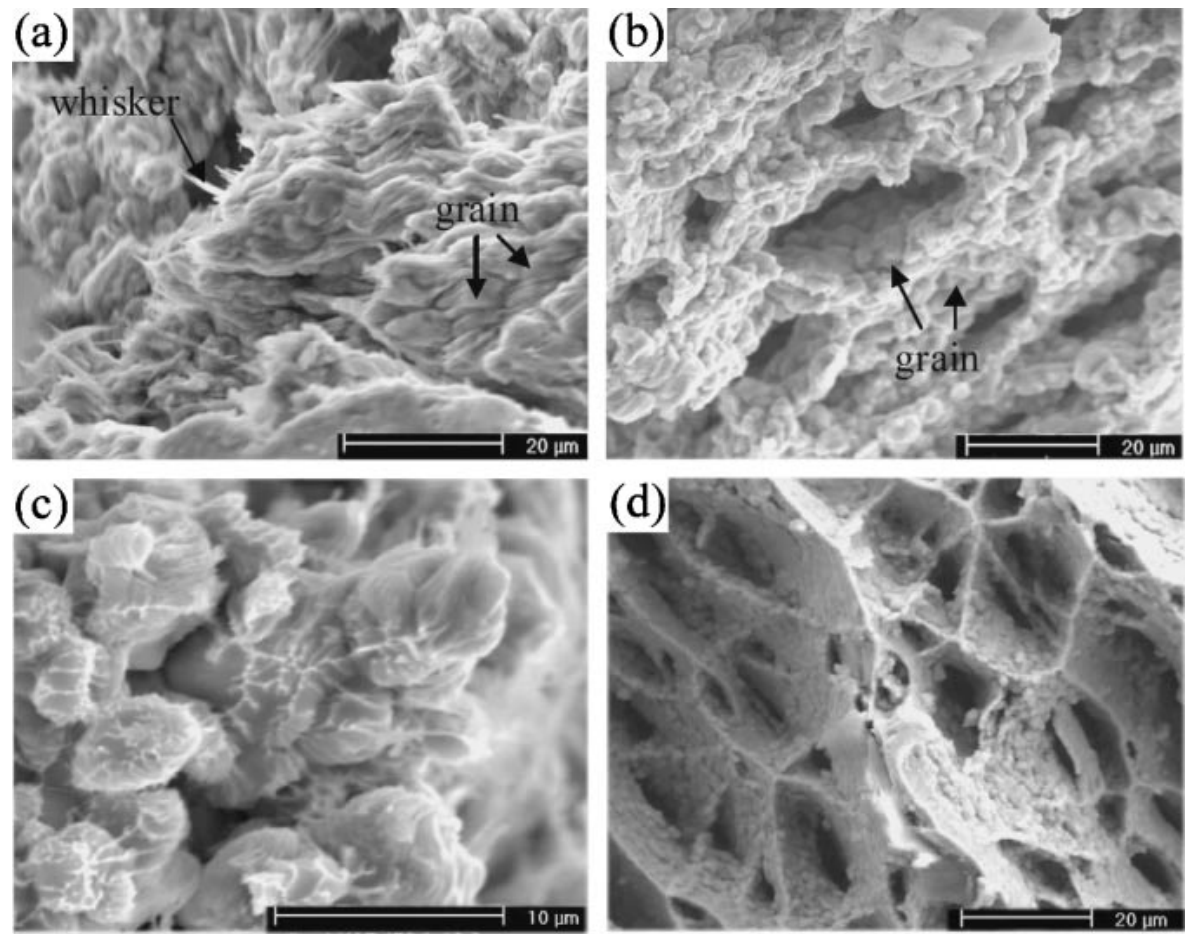

Fig. 7 SEM fractographs of (a) TMP-A and (b) TMP-B after deformed at $400^{\circ} \mathrm{C}$ and $5 \times 10^{-3} \mathrm{~s}^{-1}$; (c) TMP-A and (d) TMP-B after deformed at $450^{\circ} \mathrm{C}$ and $1 \times 10^{-2} \mathrm{~s}^{-1}$.
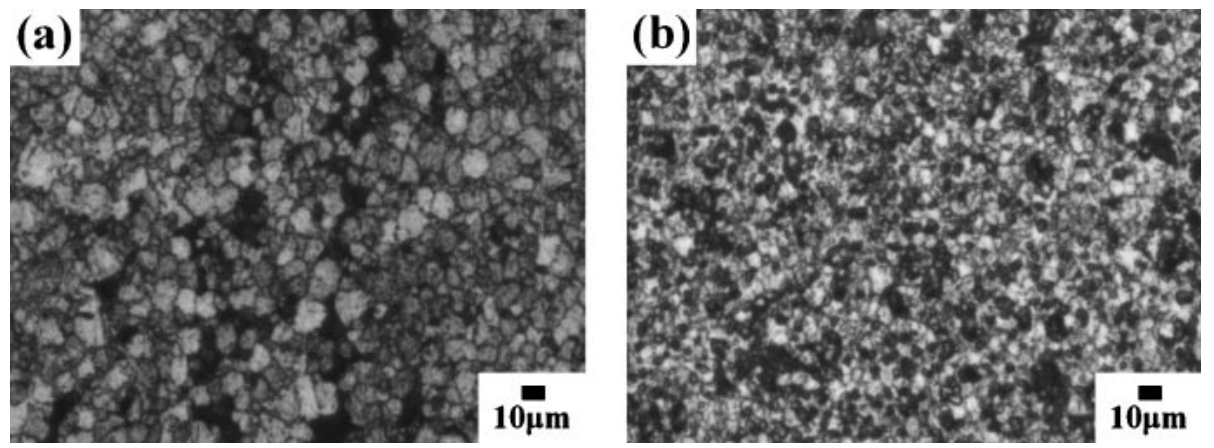

Fig. 8 Gauge sections of (a) TMP-A and (b) TMP-B after deformation at $400^{\circ} \mathrm{C}$ and $5 \times 10^{-4} \mathrm{~s}^{-1}$.

formation of $\mathrm{Al}_{3}\left(\mathrm{Sc}_{x} \mathrm{Zr}_{1-x}\right)$ particles with very attractive properties. These particles nucleate rapidly at high number densities, are homogeneously distributed, and coarsen quite slowly. ${ }^{16,17)}$ These $\mathrm{Al}_{3}\left(\mathrm{Sc}_{x} \mathrm{Zr}_{1-x}\right)$ particles stabilize the grain structure of the alloy and prevent recrystallization after hot working by pinning grain and subgrain boundaries. In our previous study, $\left.{ }^{13}\right)$ we found that $\mathrm{Al}_{3}\left(\mathrm{Sc}_{x} \mathrm{Zr}_{1-x}\right)$ particles showed significant interaction with the dislocations and grain boundaries in a cold-rolled $\mathrm{Al}-6 \mathrm{Mg}-0.4 \mathrm{Sc}-0.13 \mathrm{Zr}$ alloy at temperatures of $400^{\circ} \mathrm{C}$ and $450^{\circ} \mathrm{C}$. The $\mathrm{Al}-6 \mathrm{Mg}-0.4 \mathrm{Sc}-$ $0.13 \mathrm{Zr}$ alloy resulted in poor ductility at $400^{\circ} \mathrm{C}$ and $450^{\circ} \mathrm{C}$; it was not until the alloy was deformed at temperature above $500^{\circ} \mathrm{C}$ that the alloy exhibited excellent ductility of $1100 \%$. The $\mathrm{Al}_{3}\left(\mathrm{Sc}_{x} \mathrm{Zr}_{1-x}\right)$ particles maintain the grain structure quite effectively at very high temperatures. ${ }^{13)}$ However, without enough thermal activation, these particles act as heavily pinning nails, strongly impeding dislocation restoration and degrading grain boundary mobility during high-temperature deformation. ${ }^{13)}$ The thermal activation energy in this study was not enough to help the dislocations and grain boundaries overcome the super-high zener pinning pressure caused by the extremely fine $\mathrm{Al}_{3}\left(\mathrm{Sc}_{x} \mathrm{Zr}_{1-x}\right)$ particles at $400^{\circ} \mathrm{C}$ and $450^{\circ} \mathrm{C}$. Without the partial melting of the coarse M-phase particles, the strain energy cannot be released and the diffusion is slow, resulting in poor grain boundary mobility. This may be the reason why TMP-B ductility is less than TMP-A even though the strong pinning $\mathrm{Al}_{3}\left(\mathrm{Sc}_{x} \mathrm{Zr}_{1-x}\right)$ particles at the grain boundaries effectively maintained the fine grain structure in TMP-B after high-temperature tensile deformation.

\subsection{Strain rate sensitivity}

Figures 9(a) and (b) plot the flow stress logarithm as a function of the strain rate logarithms of TMP-A and TMP-B, respectively. TMP-A exhibits higher strain rate sensitivities (m) than TMP-B at temperatures ranging from $350-450^{\circ} \mathrm{C}$, e.g., at $350^{\circ} \mathrm{C}, \mathrm{m}_{\mathrm{A}}=0.54$ while $\mathrm{m}_{\mathrm{B}}=0.31$; at $400^{\circ} \mathrm{C}, \mathrm{m}_{\mathrm{A}}=$ 0.78 while $\mathrm{m}_{\mathrm{B}}=0.32$; at $450^{\circ} \mathrm{C}, \mathrm{m}_{\mathrm{A}}=0.70$ while $\mathrm{m}_{\mathrm{B}}=0.33$. The high $\mathrm{m}$ values of TMP-A at temperatures from $350-450^{\circ} \mathrm{C}$ were in excess of 0.5 , indicating that grain 

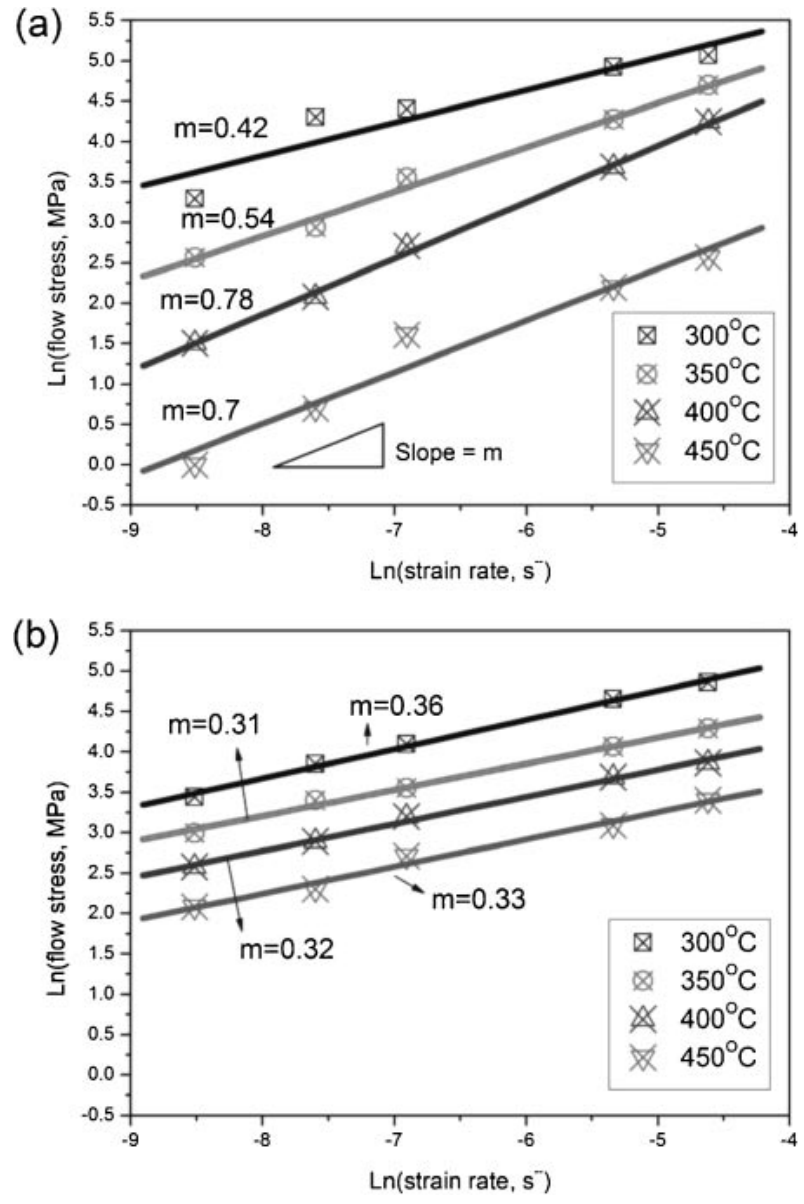

Fig. 9 Logarithm of flow stress is plotted as a function of the logarithm of strain rate: (a) TMP-A; (b) TMP-B.

boundary sliding plays an important role. This implies that the high $\mathrm{m}$ value of TMP-A is also the consequence of partial melting of M-phase particles even though the small grains in TMP-B were maintained solely by $\mathrm{Al}_{3}\left(\mathrm{Sc}_{x} \mathrm{Zr}_{1-x}\right)$ particles during high-temperature tensile deformation.

With respect to superplastic deformation, $\mathrm{Al}_{3}\left(\mathrm{Sc}_{x} \mathrm{Zr}_{1-x}\right)$ particles can not only refine the grain structure of $\mathrm{Al}$ alloys ${ }^{8)}$ but can also prevent excessive grain growth at high-temperatures. $^{5,13)}$ Though the small grain structure of TMP-B was effectively retained solely by extremely fine $\mathrm{Al}_{3}\left(\mathrm{Sc}_{x} \mathrm{Zr}_{1-x}\right)$ particles, and the grain structure of TMP-B could be smaller than TMP-A after high-temperature deformation, the elongation of TMP-B was poorer than TMP-A.

Although TMP-A overaging conducted at $400^{\circ} \mathrm{C}$ may be suitable for the precipitation and growth of $\mathrm{Al}_{3}\left(\mathrm{Sc}_{x} \mathrm{Zr}_{1-x}\right)$ particles, ${ }^{18)}$ the limited amount of $\mathrm{Sc}$ and $\mathrm{Zr}$ in the alloy restrict the coarsening kinetics of the $\mathrm{Al}_{3}\left(\mathrm{Sc}_{x} \mathrm{Zr}_{1-x}\right)$ particles. In addition, the insoluble property of these particles does not grow via Ostwald ripening mechanism. ${ }^{19}$ ) Therefore, no significant coarsening of the $\mathrm{Al}_{3}\left(\mathrm{Sc}_{x} \mathrm{Zr}_{1-x}\right)$ particles occurs in TMP-A. Assuming that the small M-phases formed during warm-rolling rapidly dissolve in the matrix and the influences of the $\mathrm{Al}_{3}\left(\mathrm{Sc}_{x} \mathrm{Zr}_{1-x}\right)$ particles during deformation in both TMP-A and TMP-B are similar, the main difference in high- temperature deformation between TMP-A and TMP-B is the existence of the coarse M-phase particles. The M-phase particles formed during overaging still play the most crucial role in enhancing the high-temperature ductility of Al-Zn$\mathrm{Mg}-\mathrm{Cu}-\mathrm{Zr}-\mathrm{Sc}$ alloys.

\section{Conclusion}

The coarse M-phase particles formed during overaging play the most crucial role in the high-temperature tensile tensile deformation of the Al-Zn-Mg-Cu-Zr-Sc alloy. These particles partially melt during high-temperature deformation, which relaxes the stress concentration, assists grain boundary sliding, and endures more cavity coalescences. Coarse Mphase particles also lead to great flow stress reduction and higher strain rate sensitivities. Since no coarse M-phase particle melt during high-temperature tensile deformation in non-overaged specimens, these specimens exhibited less ductility than overaged specimens. This result occurred despite the fact that non-overaged specimens can also maintain their small grain size at high temperature due to the existence of $\mathrm{Al}_{3}\left(\mathrm{Sc}_{x} \mathrm{Zr}_{1-x}\right)$ particles effectively retarding the grain growth.

\section{Acknowledgements}

The authors would like to thank the Chung-Shan Institute of Science and Technology (Taiwan) for financially supporting this research under Contract BV95E03P038PE.

\section{REFERENCES}

1) O. D. Sherby and J. Wadsworth: Prog. Mater. Sci. 33 (1989) 166.

2) J. A. Wert, N. E. Paton, C. H. Hamilton and M. W. Mahiney: Metall. Trans. 12A (1982) 1981-1267.

3) A. Friedman and A. K. Ghosh: Metall. Mater. Trans. A 27 (1996) 3827-3839.

4) D. H. Bae and A. K. Ghosh: Acta Mater. 48 (2000) 1207-1224.

5) S. Lee, A. A. Utsunomiya, H. Akamatsu, K. Neishi, M. Furukawa, Z. Horita and T. G. Langdon: Acta Mater. 50 (2002) 553-564.

6) H. B. Geng, S. B. Kang and B. K. Min: Mater. Sci. Eng. A 373 (2004) 229-238.

7) S. Fujikawa: J. Jap. Inst. Light Met. 49 (1999) 128-144.

8) Z. Yin, Q. Pan, Y. Zhang and F. Jiang: Mater. Sci. Eng. A 280 (2000) 151-155.

9) R. Kaibyshev, T. Sakai, F. Musin, I. Nikulin and H. Miura: Scr. Mater. 45 (2001) 1373-1380.

10) Z. Y. Ma and R. S. Mishra: Acta Mater. 51 (2003) 3551-3569.

11) D. H. Shin, C. S. Lee and W. J. Kim: Acta Mater. 45 (1997) 5195-5202.

12) W. D. Cao, X. P. Lu and H. Conard: Acta Mater. 44 (1996) 697-706.

13) Y. Y. Li, W. H. Wang, Y. F. Hsu and S. Trong: Mater. Sci. Eng. A 497 (2008) 10-17.

14) K. T. Park, D. Y. Hwang, Y. K. Lee, Y. K. Kim and D. H. Shin: Mater. Sci. Eng. A 341 (2003) 273-281.

15) X. G. Jiang, Q. Wu, J. Z. Cui and L. X. Ma: J. Mater. Sci. 28 (1993) 6035-6039.

16) V. G. Davydov, V. I. Elagin, V. V. Zakharov and D. Rostoval: Met. Sci. Heat Treat. 38 (1996) 347-352.

17) V. V. Zakharov: Met. Sci. Heat Treat. 39 (1997) 61-66.

18) J. Røyset and N. Ryum: Inter. Mater. Rev. 50 (2005) 19-44.

19) F. J. Humphreys and M. Hatherley: Recrystallization and Related Annealing Phenomena, (Oxford, Pergampn, 1995). 